\title{
A Teoria da Decisão Judicial de Robert Alexy e a Dialética Hegeliana: Um Estudo da Aplicação do Princípio da Proporcionalidade no Brasil
}

\author{
Robert Alexy's Judicial Decision Theory and Hegelian \\ Dialetics: A Study on the Application of the Proportionality \\ Principle in Brazil
}

Elda Bussinguer

(Faculdade de Direito de Vitória, Brasil)

Gabrielle Saraiva Silva (Faculdade de Direito de Cachoeiro de Itapemirim, Brasil)

Juliana Zaganelli (Faculdade de Direito de Vitória, Brasil)

\section{Resumo}

Busca-se nesse artigo analisar se a dialética hegeliana confere maior racionalidade na aplicação da teoria da decisão judicial de Robert Alexy, tendo em vista a aplicação do princípio da proporcionalidade no Brasil. Primeiramente, é apresentada a contextualização histórica da teoria da decisão judicial com o fim de, posteriormente, explicar o pensamento de Robert Alexy e suas influências teóricas no Brasil. Por fim, analisa-se qual a contribuição da dialética hegeliana na racionalidade inerente à teoria da decisão judicial no paradigma contem-porâneo, tendo em vista a importância da abordagem dialética pelo magistrado quando o mesmo se utilizada da teoria alexyana, uma vez que se torna mais racionalizada as decisões judiciais.

Palavras-chave: Teoria da Decisão Judicial. Robert Alexy. Princípio da Proporcionalidade. Dialética. Hegel.

\begin{abstract}
This article seeks to analyze if the Hegelian dialectic confers greater rationality in the application of Robert Alexy's theory of judicial decision, in view of the application of the principle of proportionality in Brazil. Firstly, the historical contextualization of the theory of judicial decision is presented in order to explain Robert Alexy's thinking and his theoretical influences in Brazil. Finally, it intends to analyze what is the contribution of the Hegelian dialectic in the rationality inherent to the theory of judicial decision in the contemporary paradigm, considering the importance of the dialectic approach by the magistrate when it is used of the alexyana theory, since it becomes more rationalized. court decisions.
\end{abstract}

Keywords: Judicial Decision Theory. Robert Alexy Proportionality principle. Dialectic. Hegel. 


\section{Introdução}

Decidir, do latim "decidere" (formado por "de" - fora e "caedere" - cortar), implica no ato de escolha de uma solução após verificação das variáveis possíveis. Segundo a etimologia da palavra, decidir significa "cortar fora" todas as outras possibilidades e decidir por uma. Nesse sentido, no âmbito jurídico, a decisão judicial se traduz na ação do magistrado em definir a resposta adequada a determinado caso concreto, demandado via ação judicial, de modo que este sujeito substitui a vontade das partes e se pronuncia resolvendo o conflito de forma livre, desde que fundamentada ${ }^{1}$.

Para conferir maior racionalidade ao dever de fundamentação dos magistrados, teóricos se ocuparam de estudar o processo deliberativo de tomada de decisão, que se inicia a partir de um problema e se direciona com o fim de se alcançar uma conclusão. Isso sistematiza o que se chama de Teorias da Decisão Judicial que, têm como expoentes, Ronald Dworkin, Jürger Habermas e Robert Alexy. Tais teorias visam elucidar quais são os critérios de uma fundamentação idônea, permitindo racionalizar o processo de escolhas, sem, contudo, objetivá-lo ao ponto de regressar aos postulados do positivismo jurídico e normativismo Kelseniano.

No Brasil, no que tange as decisões envolvendo

\footnotetext{
1 Art. 131. O juiz apreciará livremente a prova, atendendo aos fatos e circunstâncias constantes dos autos, ainda que não alegados pelas partes; mas deverá indicar, na sentença, os motivos que the formaram o convencimento. - Código de Processo Civil; Art. 93, inciso IX, CF - todos os julgamentos dos órgãos do Poder Judiciário serão públicos, e fundamentadas todas as decisões, sob pena de nulidade, podendo a lei limitar a presença, em determinados atos, às próprias partes e a seus advogados, ou somente a estes, em casos nos quais a preservação do direito à intimidade do interessado no sigilo não prejudique o interesse público à informação.
} 
Direitos Fundamentais, o Supremo Tribunal Federal (STF) tende a adotar a Teoria da Decisão Judicial de Robert Alexy como fundamento em suas decisões, invocando o princípio da proporcionalidade para balizar os princípios constitucionais. Entretanto, muito se discute sobre a importação deste modelo "à brasileira", criticando o STF pela não observância das especificidades desta teoria e as regras necessárias para a correta aplicação do princípio da proporcionalidade.

O estudo do tema se mostra relevante na atualidade, tendo em vista as inúmeras críticas à utilização do princípio da proporcionalidade pelo Supremo Tribunal Federal. Neste sentido, a proposta por um novo caminho por meio da dialética hegeliana pode imprimir maior adequação à importação da Teoria da Decisão Judicial de Robert Alexy, e com isso conferir maior efetividade ao sistema brasileiro de direitos fundamentais.

A presente pesquisa é de natureza bibliográfica, tratando-se de uma pesquisa exploratória na qual se objetiva analisar a dialética como instrumento a conferir maior racionalidade à teoria da decisão judicial no paradigma contemporâneo brasileiro, proporcionando uma adequada utilização do princípio da proporcionalidade.

\section{A teoria da decisão judicial: do normativismo kelseniano ao paradigma da incerteza}

O termo paradigma foi consolidado a partir das teorias desenvolvidas por Thomas Kunh, sobretudo em sua obra "A estrutura das revoluções científicas", em que conceituou como: “[...] realizações científicas universalmente reconhecidas que, durante algum tempo, fornece problemas e soluções modelares para uma 
comunidade de praticantes de uma ciência" 2 .

Por essa concepção, entende-se como uma interpretação de mundo de forma universal que direciona a formulação de problemas e soluções científicas seguindo uma mesma roupagem. Ademais, marca um determinado tempo e espaço, de modo que as rupturas e mudanças paradigmáticas ocorrem a partir da dinâmica social caracterizada pela dialética, assim, o paradigma dominante que sinaliza o advento da ciência moderna em meados do século XVI é calcado no modelo de racionalidade desenvolvido no império das ciências naturais ${ }^{3}$.

As ciências jurídicas, naquele momento, eram consideradas conhecimentos não científicos, assim como o senso comum, por não atender aos ditames de racionalidade e rigidez da exatidão aritmética.

Nesse contexto, "[...] o homem não poder isolar fatos/relações sociais dentro de um laboratório e de reduzir a mecânica do mundo à simplicidade do princípio da causalidade" 4. Por isso, a partir da demanda por imparcialidade e objetividade às ciências jurídicas, seguindo os postulados do positivismo filosófico de August Comte e Spencer, Hans Kelsen desenvolveu a sua Teoria Pura do Direito inaugurando o que iria se chamar de Positivismo Jurídico, com o fim de obter para o Direito o

2 KUHN, Thomas S. A estrutura das revoluções científicas. São Paulo: Editora Perspectiva, 1988, p. 13.

3 SANTOS, Boaventura de Sousa. Um discurso sobre as ciências. 12 ed. Porto: Edições Afrontamento, 2001, p. 10.

4 CRUZ, Álvaro R. de Souza. Jurisdição constitucional democrática: atualizada pela Emenda Constitucional n. 45/2004 e pelas Leis n. 11.417/2006 e 12.063/2009/ Álvaro Ricardo de Souza Cruz. - 2 ed. rev. e ampl. - Belo Horizonte: Arraes Editores, 2014, p. 139. 
status de pura ciência ${ }^{5}$.

O normativismo kelseniano, por esta lógica, reduziu o direito à dogmática da legalidade. A lei não haveria de contemplar necessariamente elementos sociais como a moral. Do mesmo modo, a decisão judicial passa a ser uma tarefa eminentemente pautada na subsunção do fato a norma. Outrossim, com Kelsen "[...] a Teoria da Decisão Judicial reduziu a jurisdição à condição de ato meramente cognitivo, no qual o julgador identificava a norma aplicável àquele conjunto de dados empíricos que se desenhavam no processo" 6 .

Com início no século XVIII, o movimento iluminista oferece o pano de fundo para novas mudanças, entre elas a ascensão das ciências sociais no século XIX, em virtude da crise do paradigma dominante das ciências modernas. O modelo de racionalidade científica, neste momento, não dá conta de explicar todos os fenômenos, sendo posto em xeque por diversos pensadores tais como Einstein com a teoria da relatividade, Gödel com o teorema da incompletude, além da mecânica quântica, princípio da incerteza de Heinsenberg e avanços na microfísica, química e biologia nos últimos vinte anos ${ }^{7}$.

Com a ruptura no paradigma clássico das ciências naturais e exatas, o novo paradigma das ciências contemporâneas introduz a preocupação com as exceções às leis formuladas, rompendo com a ideia de leis universais. As ciências exatas e naturais, neste momento, passam a lidar com a maior angústia conferida às ciências humanas e sociais: a subjetividade.

\footnotetext{
${ }^{5}$ KELSEN, Hans. Teoria Pura do Direito. Trad. de João Baptista Machado. 6. ed. São Paulo: Martins Fontes, 1998.

${ }^{6}$ CRUZ, 2014, p. 140.

7 SANTOS, 2001, p. 20/25.

134 • Ágora Filosófica, Recife, v. 20, n. 1, p. 130-153, jan./abr., 2020
} 
Einstein destruiu o conceito de que a ciência natural estivesse calcada em leis/princípios validos universal-mente. [...] Nesse sentido, Heisenberg, Bohr e o seu 'princípio da incerteza' implodiram a noção de que o cientista não interferia no objeto de sua experiência, liquidando a possibilidade de uma ciência neutra/objetiva. [...] A 'desgraça' das ciências humanas residia exatamente no fato de o cientista não poder separar-se do objeto de sua pesquisa, a sociedade. Agora, esse problema chegava às ciências naturais, pois o homem via-se, então, indissociável da natureza. ${ }^{8}$

Portanto, o paradigma contemporâneo supera o determinismo, a noção de ordem, mecanicismos, evolução e objetividade e se caracteriza pela imprevisibilidade, espontaneidade, acidente e subjetividade ${ }^{9}$. Nas ciências humanas, o paradigma contemporâneo é inaugurado por meio da "Filosofia da linguagem", sobretudo por meio dos estudos de Ludwig Wittgenstein (1970) e da hermenêutica filosófica de Martin Heidegger (1988) e Hans-George Gadamar (1977). Por estes postulados, a função da linguagem vai muito além da noção de mero “[...] instrumento de intermediação comunicativa de transmissão dos fenômenos empíricos e abstratos da ciência"10.

Nesta órbita, é imposto à ciência que se construa a partir da relação entre sujeitos, dado que o homem é entendido agora pela filosofia da linguagem, como essencialmente diálogo que se estabelece na relação sujeito/sujeito.

\footnotetext{
${ }^{8}$ CRUZ, 2014, p. 145.

9 SANTOS, 2001, p. 28.

${ }^{10}$ CRUZ, 2014, p. 147.
}

Ágora Filosófica, Recife, v. 20, n. 1, p. 130-153, jan./abr., 2020 • 135 
Logo, a ciência torna-se indissociável da subjetividade humana. Não há mais espaço para procurar-se a objetividade absoluta ou o "Santo Graal". Não existem mais fatos/eventos. A ciência e a humanidade devem reconhecer que o que se investiga são versões desses fatos/eventos, e essa concepção transpõe-se para o campo hermenêutico ${ }^{11}$.

Assim, o paradigma científico contemporâneo no Direito, e, por conseguinte, na Teoria da Decisão, são marcados pela intersubjetividade e incerteza controladas pela correção por meio dos argumentos ínsitos na decisão. Destarte, o que fiscalizará a decisão neste novo paradigma é o convencimento pela argumentação. Por isso, o estudo detido da argumentação passa ser a maior preocupação da hermenêutica no paradigma contemporâneo.

Neste contexto, o filósofo alemão Robert Alexy (2001) desenvolve a principal teoria da argumentação na contemporaneidade, a partir da "Jurisprudência de Valores" das Cortes Constitucionais europeias. ${ }^{12}$

\section{A teoria da decisão judicial alexyana}

A Teoria da Decisão Judicial de Robert Alexy consagra a técnica argumentativa da ponderação de valores constitucionais e a compreensão principiológica do Direito, especialmente o princípio da proporcionalidade

${ }^{11}$ CRUZ, 2014, p. 149.

12 BUSSINGER, Elda Coelho de Azevedo. A teoria da proporcionalidade e Robertb Alexy: uma contribuição epistêmica para a construção de uma bioética latino-americana/ Elda Coelho de Azevedo Bussinger; orientador Aline Albuquerque Sant'Ana de Oliveira. - Brasília, 2014. Tese (Doutorado Doutorado em Bioética) - Universidade de Brasília, 2014, p. 79/81.

136 • Ágora Filosófica, Recife, v. 20, n. 1, p. 130-153, jan./abr., 2020 
com o fim de racionalizar e legitimar o papel de legislador positivo. Apresenta-se como superação do normativismo kelseniano e rompe com a ideia silogística de subsunção do fato à norma que reinou durante quase mil anos. Inclusive, vai além da Tópica de Viehweg e Nova Retórica de Perelman, fazendo parte do que se denominou Comunitarismo ${ }^{13}$.

O Silogismo com origem em Aristóteles segue a seguinte lógica: tem-se uma premissa maior, uma premissa menor e uma conclusão, sendo que tais premissas devem ser verdadeiras, apesar de haver a possibilidade de serem falsas ${ }^{14}$. Assim, transportando essa ideia para a Teoria da Decisão Judicial, tem-se que uma norma abstrata se enquadraria na premissa maior, o fato na premissa menor e a sentença seria a conclusão.

Por esta sistemática o magistrado deve se ater eminentemente à literalidade da norma abstrata com o fim de subsumir o fato à norma, partindo da ideia de que todos os casos concretos se amoldariam em uma "caixinha" - normas. Não há, por esta teoria, nenhuma preocupação com as nuances do caso concreto, como se houvesse apenas uma verdade ${ }^{15}$.

A Tópica de Viehweg rompe com o tecnicismo positivista, valorizando as peculiaridades do caso concreto. Por este motivo, a Tópica acrescenta um novo colorido à Teoria da Decisão Judicial que até este momento era ventilada pelo Silogismo. É impossível,

\footnotetext{
13 ADEODATO, João Maurício Leitão. Norma Jurídica como Decisão dotada de efetividade. Revista Jurídica da Presidência. Brasília. v. 15. n. 106, jun./set. 2013, p. 327-328.
}

${ }^{14}$ ARISTÓTELES. Volume I. Seleção de textos de José Américo Motta Pessanha. Trad. de Leonel Vallandro e Gerd Bornheim. São Paulo: Nova Cultural, 1987, p. 14. (Os Pensadores.)

${ }^{15}$ ADEODATO, 2013, p. 327-328. 
diante disso, pensar em uma Teoria da Decisão Judicial eminentemente em termos silogísticos, com a supervalorização do conhecimento da norma, em detrimento das circunstâncias do caso concreto.

Era, pois, uma resposta direta à 'espada de Dâmocles colocada pela concepção voluntarista/discricionária da Teoria da Decisão de Kelsen (1979), isto é: o operador do Direito que, segundo o normativismo, não tinha um critério normativo objetivo que regulasse a correção de sua decisão, passava a regular-se pelo grau de convencimento causado pela fundamentação de sua decisão. Naquele momento, ele desenvolveu/valorizou o elemento dialético, qual seja, o de disputa argumentativa na construção da decisão[...] $]^{16}$.

Neste momento, a dialética na Teoria da Decisão Judicial valoriza as diversas vertentes do caso concreto com o fim de trazer ao debate todas as dimensões do problema, de modo a promover a mais ampla discussão, facilitando assim abordagem de questões complexas ${ }^{17}$.

Perelman, no mesmo sentido, desenvolveu a Nova Retórica adotando a lógica dialética com fins de "procedimentalizar controvérsias" através do discurso. A Decisão Judicial deveria avaliar o que é mais razoável para determinado caso usando da equidade, como meio de justificação da decisão. Isso porque, "[...] a ponderação de valores e adesão dos participantes no processo seria a maneira mais adequada de apreciação de casos complexos. ${ }^{\prime 18}$

\footnotetext{
${ }^{16}$ CRUZ, 2014, p. 154.

17 CRUZ, 2014, p. 155.

$18 \mathrm{CRUZ}, 2014$, p. 156.
}

138 • Ágora Filosófica, Recife, v. 20, n. 1, p. 130-153, jan./abr., 2020 
O Comunitarismo, mais adiante, se desenvolve como meio termo entre o marxismo e o liberalismo, entendendo os valores comunitários como produto das relações dialógicas entre os indivíduos e a comunidade. Percebe a comunidade como espaço plural em que o conteúdo moral desta só se extrai de um amplo diálogo entre os interessados. Partindo desta premissa, o Comunitarismo agrega ao Direito a visão plural de mundo e a necessidade de se abrir ao diálogo de ideias e valores da comunidade, em respeito às peculiaridades de cada uma delas, como instrumento racional da própria ideia de justiça.

Com isso, a Teoria da Decisão Judicial passa a valorizar o conteúdo axiológico das decisões judiciais que agora deve estar calcada nos valores concretos de uma dada comunidade. Nesse ínterim, as "[...] Cortes Constitucionais estariam ligadas necessariamente a uma eticidade material, que equiparava as normas constitucionais, especialmente seus princípios, aos valores supremos da comunidade". ${ }^{19}$ Desse modo, a "Jurisprudência de Valores" sustentou seus postulados na Tópica de Viehweg, Nova Retórica de Perelman e no Comunitarismo, negando a lógica silogística empreendida por Aristóteles.

Neste cenário, Robert Alexy empreendeu sua Teoria da Argumentação com fins de agregar critérios de correção às decisões judiciais a partir da Tópica. Por não haver nenhum critério lógico de aferição das decisões até então, era preciso acrescentar um "plus" de racionalidade a esta nova Teoria da Decisão Judicial que se desenvolveu na contemporaneidade pós-Kelsen. Alexy, reconhecendo a

${ }^{19}$ CRUZ, 2014, p. 140.

Ágora Filosófica, Recife, v. 20, n. 1, p. 130-153, jan./abr., 2020 • 139 
supremacia dos princípios constitucionais no Ordenamento Jurídico, preocupou-se com a ética discursiva e com o exame das regras de linguagem, não se desvencilhando, contudo, da concretude dos fatos na argumentação.

A fim de conferir maior proteção aos direitos fundamentais, erigiu sua teoria da argumentação dando ênfase ao aspecto dialógico do discurso e à racionalidade do "princípio da proporcionalidade". Nesse sentido, em Alexy os discursos racionais práticos, preocupados com a correção, passaram a se ater a justificação de critérios de forma normativa, inerentes à racionalidade. Era preciso coerência e sinceridade dos julgadores.

Além disso, deveria expor as razões que justificariam tal decisão. Ademais, deveria estar aberto a qualquer tipo de contrarrazão de quem questionasse suas justificações. Essas seriam, em suma, as regras da racionalidade ${ }^{20}$. Alexy não ignorou o fato de que existem inúmeras formas de se argumentar, e dessa forma, poderiam resultar em produções contraditórias. Por isso, enumerou algumas "regras de justificação" que estabeleceriam uma ordem preferencial entre os argumentos, entre elas o princípio da universalidade de Hare e da reciprocidade de Habermas.

Desse modo, a Teoria da Decisão de Alexy (2001) pretendeu permitir o exame de um ordenamento jurídico lacunoso e contraditório, de forma a controlar a subjetividade do julgador, por meio de uma racionalidade dialógica e vinculada ao teste de um debate público para aferição da correção das decisões. Ele reconheceu a falácia positivista de uma racionalidade

20 BUSSINGER, 2014, p.159,160.

140 • Ágora Filosófica, Recife, v. 20, n. 1, p. 130-153, jan./abr., 2020 
absoluta/objetiva, e, com isso, procurou reconstruí-la no seio da intersubjetividade da argumentação jurídica. ${ }^{21}$

Quanto ao princípio da proporcionalidade, depreende-se que sua correta utilização perpassa por 03 (três) subprincípios, quais sejam: adequação, necessidade e proporcionalidade em sentido estrito ("Lei do balanceamento"). ${ }^{22}$ Alexy entende os princípios enquanto "comandos de otimização", de modo que de acordo com as condições fáticas e jurídicas algo deva ser realizado na maior medida possível.

A Teoria da Decisão Judicial desenvolvida por Robert Alexy, consiste em uma Teoria da Argumentação pautada no diálogo racional entre os valores comunitários, com reconhecimento da supremacia dos princípios constitucionais e utilização do princípio da proporcionalidade para ponderar direitos fundamentais.

O STF ao julgar casos envolvendo direitos fundamentais adota a Teoria da Decisão Judicial de Robert Alexy como método. Entretanto, muitas críticas se tecem a esta aplicação metodológica de Robert Alexy "à brasileira", em razão de uma consistir em uma prática "rasa e superficial".

O Supremo Tribunal Federal, apesar de ter assumido a Teoria Alexyana como método de resolução de conflitos envolvendo Direitos Fundamentais, parece utilizá-la, ainda, de forma rasa e superficial, contentando-se, em suas decisões, a citar o princípio sem, contudo, sustentar sua utilização a partir de

${ }^{21}$ CRUZ, 2014, p. 176.

22 ALEXY, Robert. Direitos fundamentais, balanceamento e racionalidade. Ratio Juris. Vol. 16, n. 2, junho de 2003, p.5. 
um raciocínio argumentativo com a solidez e a consciência que um processo dessa natureza requer e tal qual o temos visto em decisões de tribunais alienígenas. ${ }^{23}$

Portanto, a aplicação desta teoria no Brasil se mostra inadequada por importar superficialmente 0 método às decisões judicias, sem maiores preocupações com a argumentação racional e concreta inerente a este modelo proposto por Robert Alexy.

\section{Da aproximação entre a dialética hegeliana e a teoria da decisão judicial de Robert Alexy: a dialética como método de decisão judicial}

O conceito dialético na Grécia Antiga denotava a ideia de "diálogo", que posteriormente passou a exprimir a "arte de, no diálogo, demonstrar uma tese por meio de uma argumentação capaz de definir e distinguir claramente os conceitos envolvidos na discussão"24. Hoje, no entanto, entende-se a dialética como a maneira pela qual as contradições da vida são ponderadas, entendendo a realidade como essencialmente contraditória e em constante mudança.

Para delimitar os estudos acerca da dialética, o filósofo escolhido para nortear o presente trabalho foi Georg Wilhelm Friedrich Hegel. É por meio da dialética hegeliana que são criadas três etapas, sendo a primeira a lógica do ser, a qual a dialética "procede em sentido horizontal"; a lógica da essência, apresenta ideias mais profundas, no sentido de "desenvolver-se e refletir-se"; e,

\footnotetext{
23 BUSSINGER, 2014, p.90.

${ }^{24}$ KONDER, Leandro. 0 que é dialética. São Paulo: Editora Brasiliense, 1999, p. 7.

142 • Ágora Filosófica, Recife, v. 20, n. 1, p. 130-153, jan./abr., 2020
} 
por fim, a lógica do conceito, o pensamento é completo. $\mathrm{O}$ movimento do espírito é o de "refletir-se em si mesmo", retratando o ciclo, que em um primeiro momento é a ideia em si" (lógica); a "ideia fora de si" (filosofia da natureza); e a "ideia ser em si e para si" (filosofia do espírito) ${ }^{25}$.

Desse modo, a filosofia da história em Hegel só é compreendida a partir desse movimento, na ideia em si, fora de si e o retorno histórico a si, cuja situação se retrata por meio da filosofia do espírito. No que se refere aos núcleos conceituais que envolvem os fundamentos do sistema de Hegel são três, o primeiro é a "realidade enquanto tal é espírito infinito"; o segundo é a estrutura, a qual é "a própria vida do espírito [...] e o procedimento que desenvolve a dialética"; por fim, a peculiaridade da dialética é o elemento "especulativo" 26.

O nó fundamental do pensamento de Hegel é considerar a verdade como sujeito/espírito em movimento, de forma dinâmica que se renova. Nesse sentido, o método dialético de Hegel propõe um embate entre a razão e a realidade, com seu caráter processual ${ }^{27}$. Assim, a dialética

[...] não consiste em produzir e conceber a determinação apenas como limite e contrário, mas sim consiste em produzir e apreender, a partir dela, o conteúdo e o resultado positivos, enquanto por este meio a dialética é unicamente desenvolvimento e progredir imanente ${ }^{28}$.

\footnotetext{
25 REALE, Giovanni; DARIO, Antiseri. História da Filosofia: Do Romantismo ao Empiriocriticismo. V. 5. São Paulo: Editora Paulus, 2007, p. 103-104.

${ }^{26}$ REALE; DARIO, 2007, p. 100-101.

27 HEGEL. Georg Wilhelm Friedrich. Vida e Obra. Coleção Os Pensadores. Trad. Henrique Cláudio de Lima Vaz. São Paulo: Editora Abril Cultural, 1980, p. $X X$.

28 HEGEL, Georg Wilhelm Friedrich. Princípios da Filosofia do Direito. Trad. Ágora Filosófica, Recife, v. 20, n. 1, p. 130-153, jan./abr., 2020 • 143
} 
O método dialético é um motor que "[...] se desenvolve a partir de si mesmo, progride e produz as suas determinações de maneira imanente." ${ }^{29}$, ao invés de aplicar de modo arbitrário, sendo o único método capaz de elevar a filosofia à ciência. Considerado um dos mais profundos renovadores da teoria do Estado, por conta de seu pensamento político e organicista, além de sua filosofia idealista, a qual reside no fato de definir o Universo por meio do movimento dinâmico ${ }^{30}$, a realidade, para Hegel, deveria ser compreendida em torno da própria dialética, a qual

[...] é o processo mediante o qual a razão se reconhece na realidade que surge como estranha ou oposta à razão, suprimindo ou conciliando essa oposição mas é ainda o processo mediante o qual a realidade se concilia consigo própria e age na sua unidade racional, superando as diferenças, as divisões, as oposições que constituem os aspectos particulares e apaziguando-se na unidade do todo ${ }^{31}$.

Tais movimentos demonstram o caráter dialético, tendo em vista que a razão é compreendida em torno de uma realidade, sendo que esta se concilia consigo própria, enfatizando as contradições existentes. Por isso, a necessidade de pormenorizar os três momentos do movimento dialético, que consistem basicamente na

Norberto de Paula Lima. São Paulo: Editora Ícone, 1997, p. 62.

29 HEGEL, 1997, p. 62.

30 BONAVIDES, Paulo. Do Estado Liberal ao Estado Social. 10 ed. São Paulo: Editora Malheiros, 2012, p. 119-120.

31 ABBAGNANO, Nicola. História da Filosofia. Trad. Armando da Silva Carvalho. Vol. 9. Lisboa: Editorial Presença, 2003, p. 113-114.

144 • Ágora Filosófica, Recife, v. 20, n. 1, p. 130-153, jan./abr., 2020 
tríade: tese (afirmação), antítese (negação) e síntese.

Isto posto, a tese, "momento abstrato ou intelectivo"32 é a primeira afirmação de uma dada realidade, até porque para afirmar determinada situação, outras condicionantes foram ignoradas, desencadeando em um conhecimento inadequado. Já a antítese, "lado dialético ou negativamente racional" 33 seria o desenvolvimento de todas as contradições, isto é, ir além dos limites abstratos ou intelectuais para sua superação, ou seja, para gerar uma nova realidade, uma nova perspectiva.

Em suma, após a tese trazer uma afirmativa que, posteriormente, será negada pela antítese, há o terceiro momento: a chamada síntese. Nesse momento "especulativo" ou "positivamente racional", a "[...] razão capta a unidade das determinações contrapostas, ou seja, capta dentro de si o positivo emergente da síntese dos opostos e se mostra ela própria como totalidade completa"34, logo, há um consenso entre o que foi estabelecido na tese e na antítese, formando uma síntese.

A dialética, nesse caso, é considerada como: a "síntese dos opostos", exigindo um processo "[...] conciliador e sintético, no qual as divisões ou as oposições da realidade apareçam ao mesmo tempo justificadas como tais e superadas na unidade de uma síntese" ${ }^{\prime 35}$. Diante disso, é possível afirmar que o método dialético hegeliano condiz com a realidade, uma vez que esta se apresenta em um processo dinâmico e não estático, por meio do movimento triádico tese-antítese-síntese.

\footnotetext{
32 REALE; DARIO, 2007, p. P. 108.

33 REALE; DARIO, 2007, p. P. 108.

34 REALE; DARIO, 2007, p. p. 100.

35 ABBAGNANO, 2003, p. 114.
} 
A partir destas premissas, extrai-se que a ideia central da dialética é a existência dos contrários, tanto que Hegel, um dos principais teóricos da dialética, fundamenta-se nas contradições buscando a plenitude. Com isso, não há esgotamento do seu fim, mas uma atualização, como bem ressalta Hegel, tendo em vista que a contradição é um momento necessário que deve ser superado, justamente, para que o desenvolvimento não acabe. Tem-se, a partir disso, que,

O botão desaparece no desabrochar da flor, e poderia dizer-se que a flor o refuta; do mesmo modo que o fruto faz a flor parecer um falso ser-aí da planta, pondo-se como sua verdade em lugar da flor: essas formas não só se distinguem, mas também se repelem como incompatíveis entre si. Porém, ao mesmo tempo, sua natureza fluida faz delas momentos da unidade orgânica, na qual, longe de se contradizerem, todos são igualmente necessários. É essa igual necessidade que constitui unicamente a vida do todo ${ }^{36}$.

Os processos de mudanças são ensejados pelas contradições existentes dentro de uma determinada situação, de modo que quanto mais profunda e radical as contradições, mais profunda e radical será a mudança engendrada. Trazendo esses conceitos à Teoria da Decisão Judicial, sobretudo, com o fim de conferir maior racionalidade a aplicação do princípio da proporcionalidade pelo Supremo Tribunal Federal, pode-se afirmar que a essência de um processo judicial, portanto, é a

\footnotetext{
${ }^{36}$ HEGEL, Georg Wilhelm Friedrich. Fenomenologia do Espírito. Trad. Paulo Meneses. Rio de Janeiro: Editora Vozes, 2002, p. 26.

146 • Ágora Filosófica, Recife, v. 20, n. 1, p. 130-153, jan./abr., 2020
} 
existência dos contrários, ou seja, existência de contradições internas nascidas a partir de um fato que dá origem à lide e, por fim, ao processo.

A estrutura processual é essencialmente dialética, de modo que a lide é a tese, as diferentes versões de fato e de direito, as antíteses, sendo a sentença a síntese dialética. Pelo exposto, a proposta do trabalho é exatamente analisar se há ou não um déficit dialético nos tribunais brasileiros, por meio de uma perspectiva equivocada da utilização da Teoria Alexyana, uma vez que para Hegel, a dialética é o único método capaz de elevar a filosofia à ciência.

Ao assumir a utilização do princípio da proporcionalidade, no que diz respeito, principalmente, aos direitos fundamentais, os Tribunais Superiores brasileiros deveriam ter uma jurisdição mais coerente para não desaguar na falta de uniformidade e de sistematicidade ${ }^{37}$. Nas decisões judiciais, é dever do magistrado solucionar o conflito existente qualificado como a lide exarando um provimento jurisdicional denominada sentença.

Mais do que isso, é dever do magistrado zelar pelo cumprimento de todas as garantias processuais no deslinde da lide, entre elas, o exercício do contraditório que visa assegurar a participação dos interessados na formação do convencimento do magistrado. O contraditório, em suma, garante aos interessados a distribuição equitativa de poderes e deveres, de modo a equilibrar as posições contraditórias.

As partes, por sua vez, devem instruir o processo apresentando ao juiz os fundamentos de fato e de direito

37 BUSSINGER, 2014, p. 91.

Ágora Filosófica, Recife, v. 20, n. 1, p. 130-153, jan./abr., 2020 • 147 
que corroboram o seu pleito. Para tanto, é lícito apresentarem versões fáticas antagônicas, bem como apresentarem diferentes interpretações do direito posto, utilizando-se de teses e até mesmo jurisprudência contraditórias. No entanto,

Muitos juízes, deslumbrados diante dos princípios e da possibilidade de, através deles, buscarem a justiça - ou o que entendem por justiça -, passaram a negligenciar do seu dever de fundamentar racionalmente os seus julgamentos. Esta 'euforia' com os princípios abriu um espaço muito maior para o decisionismo judicial. Um decisionismo travestido sob as vestes do politicamente correto, orgulhoso com os seus jargões grandiloqüentes e com a sua retórica inflamada, mas sempre um decisionismo. Os princípios constitucionais, neste quadro, converteram-se em verdadeiras 'varinhas de condão': com eles, o julgador de plantão consegue fazer quase tudo o que quiser ${ }^{38}$.

A dialética é um sistema, uma construção lógica e racional que pretende apreender o real em sua totalidade pela lógica do conflito. A tese e a antítese são abstrações ou momentos de um processo em que ambos são superados pela síntese, a sentença é, assim, o resultado dos contraditórios, por isso, é dialética em si mesma. É válido mencionar que

[...] uma vez que a lei não-escrita está contida nas decisões dos tribunais e dos juízes, estes ficam sendo perpétuos legisladores, e tanto

38 SARMENTO, Daniel. Livres e Iguais: Estudos de Direito Constitucional. São Paulo: Lúmen Juris, 2006, p. 200.

148 • Ágora Filosófica, Recife, v. 20, n. 1, p. 130-153, jan./abr., 2020 
se pode dizer que os juízes devem refletir-se à autoridade dos seus predecessores [...] como que não devem fazê-lo, pois eles mesmos dispõem dessa mesma lei com igual autoridade. De fato, é concedido a eles o direito de em uma sentença se pronunciarem sobre decisões precedentes, considerando-as conformes, ou não, a essa lei ${ }^{39}$.

O magistrado, sujeito desse processo deve-se pautar nas premissas, no intuito de adequar os fatos trazidos aos autos à norma preexistente, deve avaliar todos os contrários trazidos pelas partes (versões diversas e interpretações normativas diversas) para entender as antíteses e, assim, com base no discurso racional, prolatar sua sentença que é a síntese dialética.

É possível perceber que a estrutura dialética aplicada na decisão judicial permite o controle da decisão, já que impõem a fundamentação de todas as versões fáticas trazidas (antíteses fáticas) e de todas as teses jurídicas, interpretações jurídicas opostas (antíteses jurídicas).

Com a aplicação do método dialético, a decisão judicial se reveste de racionalidade vez que impõe uma fundamentação persuasiva e racional de todos os pontos de vista, preenchendo muito mais que o requisito formal imposto à sentença, qual seja, a existência da fundamentação. Vale mencionar que Hegel valorizava as contradições na linguagem ao perceber que as palavras tinham mais de um sentido opostos ou não,

Pode ser uma alegria para o pensamento encontrar-se com tais palavras e verse na

39 HEGEL, 1997, p. 184.

Ágora Filosófica, Recife, v. 20, n. 1, p. 130-153, jan./abr., $2020 \cdot 149$ 
presença da união dos contrários, contida de maneira ingênua e segundo o léxico de uma só palavra de significados opostos; cuja união é um resultado da especulação apesar de ser contraditória para o intelecto ${ }^{40}$.

Nota-se que a fundamentação de uma decisão judicial permite que quem não obteve sucesso, entenda os motivos que levou ao magistrado se posicionar daquela forma para que, inclusive, possa recorrer, em caso de não corroborar com o que foi trazido em tal decisão. Isso permite com que o vencido possa recorrer e modificar o que foi decidido, efetivando seus direitos de modo a se alcançar a "justiça".

Portanto, a decisão judicial, a partir da abordagem dialética, deixa de ser uma técnica abstrata para proporcionar uma maior efetivação dos direitos e garantias constitucionais a partir da problematização do caso concreto.

\section{Conclusão}

O presente trabalho estudou a Teoria da Decisão de Robert Alexy aplicada ao Brasil, sobretudo quanto à aplicação do princípio da proporcionalidade, com o fim de verificar se a dialética hegeliana poderia conferir maior racionalidade para uma adequada utilização desta.

A partir deste estudo, percebe-se a importância da abordagem dialética pelo magistrado com o fim de

\footnotetext{
40 Puede ser una alegría para el pensamiento encontrarse con tales palabras y verse en presencia de la unión de los contrarios, contenida de manera ingenua y según el léxico en una sola palabra de significados opuestos; cuya unión es un resultado de la especulación a pesar de ser contradictoria para el intelecto. (HEGEL, Georg Wilhelm Friedrich. Ciencia de la lógica. Buenos
} Aires: Ediciones Solar y Libreria Hachette, 1968, p. 32).

150 • Ágora Filosófica, Recife, v. 20, n. 1, p. 130-153, jan./abr., 2020 
racionalizar a argumentação e assim efetivarem-se direitos e garantias fundamentais de forma racional e dialógica, e, por conseguinte permitir a correção nas decisões judiciais.

Com o uso da abordagem dialética, há uma impossibilidade do magistrado ou qualquer outro operador do Direito manipular as premissas silogísticas, sendo necessário partir de uma argumentação práticoracional, com base no comunitarismo, com uma maior preocupação com a dialeticidade do caso concreto e com a própria garantia do princípio Constitucional do Contraditório.

É preciso, portanto, romper com a prática reducionista de aplicação do princípio da proporcionalidade de forma rasa e superficial, para que o magistrado tenha uma visão macro de todas as vicissitudes do processo, proporcionando uma maior efetividade dos direitos elencados pela Magna Carta.

\section{Referências}

ABBAGNANO, Nicola. História da Filosofia. Trad. Armando da Silva Carvalho. Vol. 9. Lisboa: Editorial Presença, 2003.

BONAVIDES, Paulo. Do Estado Liberal ao Estado Social. 10. ed. São Paulo: Editora Malheiros, 2012.

BRASIL. Lei 5.869, de 11 de janeiro de 1973. Código de Processo Civil. Diário Oficial da União, Brasília, 17 jan. 1973.

BRASIL. Constituição da República Federativa do Brasil. Brasília, DF: Senado Federal: Centro Gráfico, 1988. BUSSINGER, Elda Coelho de Azevedo. A teoria da proporcionalidade e Robertb Alexy: uma contribuição epistêmica para a construção de uma bioética latino- 
americana/ Elda Coelho de Azevedo Bussinger; orientador Aline Albuquerque Sant'Ana de Oliveira. - Brasília, 2014. Tese (Doutorado - Doutorado em Bioética) - Universidade de Brasília, 2014, p. 90.

CRUZ, Álvaro Ricardo de Souza. Jurisdição constitucional democrática: atualizada pela Emenda Constitucional n. 45/2004 e pelas Leis n. 11.417/2006 e 12.063/2009/ Álvaro Ricardo de Souza Cruz. - 2 ed. rev. e ampl. - Belo Horizonte: Arraes Editores, 2014.

KELSEN, Hans. Teoria Pura do Direito. Traduzido por João Baptista Machado. 6.ed. São Paulo: Martins Fontes, 1998 KONDER, Leandro. $\mathbf{O}$ que é dialética. São Paulo: Editora Brasiliense, 1999.

KUHN, Thomas S. A estrutura das revoluções científicas. São Paulo: Editora Perspectiva, 1988.

Os Pensadores. Aristóteles. Volume I. Seleção de textos de José Américo Motta Pessanha. Tradução de Leonel Vallandro e Gerd Bornheim da versão inglesa de W.A. Pickard. São Paulo: Nova Cultural, 1987.

REALE, Giovanni; DARIO, Antiseri. História da Filosofia: Do Romantismo ao Empiriocriticismo. V. 5. São Paulo: Editora Paulus, 2007.

RECK, J. R. Observação Pragmático-Sistêmica do Silogismo Jurídico e sua Incapacidade em Resolver o Problema da Definição do Serviço Público. Revista do Direito UNISC, Santa Cruz do Sul. n. 37, p. 31-52, Jan-Jun 2012.

SANTOS, Boaventura de Sousa. Um discurso sobre as ciências. 12. ed. Porto: Edições Afrontamento, 2001.

SARMENTO, Daniel. Livres e Iguais: Estudos de Direito Constitucional. São Paulo: Lúmen Juris, 2006.

STREAK, Lênio apud GOMES, Matheus Barreto. Precedentes judiciais legitimação pelo procedimento. Dissertação apresentada ao Programa de Pós- graduação 
em Direito, Faculdade de Direito, Universidade Federal da Bahia, Salvador, 2009.

HEGEL, Georg W. F. Ciencia de la lógica. Buenos Aires: Ediciones Solar y Libreria Hachette, 1968.

HEGEL, Georg W. F. Fenomenologia do Espírito. Trad. Paulo Meneses. Rio de Janeiro: Editora Vozes, 2002. HEGEL, Georg W. F. Princípios da Filosofia do Direito. Trad. Norberto de P. Lima. São Paulo: Editora Ícone, 1997. HEGEL. Georg Wilhelm Friedrich. Vida e Obra. Coleção Os Pensadores. Trad. Henrique Cláudio de Lima Vaz. São Paulo: Editora Abril Cultural, 1980.

Marina Maria Soares Silva

Pós-doutora em Saúde Coletiva pela Universidade Federal do Rio de Janeiro (UFRJ). Coordenadora do Programa de Pós Graduação em Direito da Faculdade de Direito de Vitória.

E-mail: elda@fdv.br

Gabrielle Bandeira

Mestra em Direitos e Garantias Fundamentais pela FDV. Professora da FDCI. Advogada.

E-mail: gabriellesaraiva.s@gmail.com

Juliana Zaganelli

Doutoranda em Direitos e Garantias Fundamentais pela Faculdade de Direito de Vitória. Participante "Doctoral Networking Sessions" pela The Hague Academy of International Law.

E-mail: julianazaganelli@gmail.com

Submetido: 07/01/2020

Aprovado: 07/03/2020 